\title{
An Analysis of Errors in English Writing Made by Chinese and Korean University Students
}

\author{
Cui Zheng \\ School of International Exchange, Shandong Normal University, Jinan, China \\ Tae-Ja Park \\ English Education Department, Korea University, Seoul, South Korea
}

\begin{abstract}
This study adopted Kim (2009)'s error classification system, based on from Dulay, Burt and Krashen (1982)'s linguistic classification of errors. Errors in 168 English essays written by Chinese and Korean university students were identified and coded by three coders using NVivo. The analysis shows that some errors such as run-on sentences, the omission of articles and plural suffix-s, and sentence misordering can be caused by the negative transfer from learners' first language. This phenomenon is highlighted by the contrastive analysis hypothesis (CAH). In Chinese, for example, commas are used in a multifunctional way. They can be used as either periods or conjunctions, which results in run-on sentences and the omission of conjunctions in English. No articles exist in the Chinese and Korean languages, which is also the reason for the omission of English articles. Different use of plural forms in Chinese and Korean makes it difficult for EFL learners to master in English. The Korean SOV structure also confuses many Korean university students when they construct their English SVO sentences. Meanwhile, some errors can be caused just because of learners' own creative construction regardless of their first language background, such as the misformation of verbs and nouns. This error cluster is illustrated by the creative construction hypothesis $(\mathrm{CCH})$. The results indicate that both the occurrence of $\mathrm{CAH}$ and $\mathrm{CCH}$ are reasonable to some extent. The comparative analysis of errors in English writing made by Chinese and Korean university students shows a general picture of common errors made by these English learners as comprised of both $\mathrm{CAH}$ and $\mathrm{CCH}$ type errors. The reasons these errors were made are also explored, especially reasons related to their first language.
\end{abstract}

Index Terms - classification of errors, contrastive analysis hypothesis, creative construction hypothesis, first language transfer, error analysis

\section{INTRODUCTION}

In the 1960s, Error Analysis (EA), which studies the types and causes of language errors, developed as an alternative to the Contrastive Analysis (CA) approach in applied linguistics. Corder (1981) explained two rationales for conducting error analysis: theoretical reason and practical reason. Theoretically, he claimed error analysis could help in the investigation of the language learning process. Practically, it can guide the remedial actions teachers need to make in order to correct the errors for learners.

Error analysis may seem to some to be an outdated theory, because it was proposed in 1960s, then criticized and replaced by interlanguage theory (Selinker, 1992). However, this approach is still, no doubt, very useful in English language learning and teaching. It has proven useful for teachers to use to diagnose English learners' writing problems, analyze the reasons for these problems and thus provide effective remedies. This paper collected, identified, analyzed, and described the errors in English essays written by Chinese and Korean university students. As EFL learners belonging to the Asian cultural circle, Chinese and Korean English learners may exhibit both similarities and differences in their English writing. This paper thus focuses on the errors made in the English essays of Chinese and Korean university students, hoping that identification of the similarities and differences between the Korean and Chinese students' errors in writing could help English teaching and learning in China and Korea.

\section{BACKGROUND AND PREVIOUS RESEARCH}

\section{A. Contrastive Analysis Hypothesis (CAH) vs. Creative Construction Hypothesis (CCH)}

Lado (1957) (as cited in Ellis, 2008, p. 359) claimed that when a learner learns a second language, the elements in L2 which are similar to the learner's L1 will be easy for him, while elements which are different from the learner's L1 will be difficult. CAH as formulated by Lado implies that learner's L1 has a great influence on his L2 learning. L1 determines to some extent whether a learner can learn L2 successfully.

$\mathrm{CCH}$ was first proposed by Dulay and Burt (1973). It is an opposite hypothesis from CAH. According to CCH, a learner's L1 does not have much influence on the acquisition of a L2. Dulay and Burt (1973, 1974, as cited in Ellis, 1985, pp. 28-29) conducted an empirical study calculating the frequency of error types made by L2 children learners. 
They found that children do not organize a L2 based on their L1 transfer or comparison. They construct their own L2 structure in a creative way.

Now the question is which of these two theories is more convincing in terms of the English essays written by Chinese and Korean university students? This study provides evidence in support of both of these theories.

\section{B. Classification of Errors}

There are different error taxonomies that have been constructed over the years, classified from a variety of perspectives. Dulay, Burt and Krashen (1982) summarized error types using four different taxonomies: error types based on linguistic category (morphology and syntax), surface strategy taxonomy (the skeleton of English clauses, the auxiliary system, passive sentences, temporal conjunctions, sentential complements and psychological predicates), comparative taxonomy (developmental errors and interlingual errors) and communicative effect taxonomy (global errors, local errors and psychological predicates). This study adopts Kim (2009)'s error classification system, which is based on Dulay and Burt and Krashen's classification system. Four types of errors with their subcategories are identified and coded in this study: misformation, omission, addition, and other.

\section{Previous Research}

As mentioned, error analysis is not a new theory, but it has still proven to be very useful and practical in language teaching. That is why in recent years many English teachers and educators are still researching error analysis, either empirically or just theoretically.

Xing (2007), for example, summarized the classification, sources and significance of errors. However, she failed to focus on error analysis in English language teaching in China. Yang (2010) described the different types of errors and highlighted the fact that errors may not always be caused by the influence of L1; they could also reflect some common learning strategies. Heydari and Bagheri (2012) provided an overview of almost all the previous research in the field of error analysis, hoping that EFL teachers and educators could become more familiar with students' errors and thus utilize appropriate teaching strategies along with their colleagues and learners.

Some researchers conducted the empirical studies. Muriungi, Mukuthuria and Gatavi (2011), for example, explored an English error study in a primary school in Kenya. They collected students' English essays, investigated the nature and typology of errors, and provided some remedies for these errors. Yahya, Ishak, Zainal, Faghat and Yahaya (2012) identified and analyzed secondary school students' errors in narrative and descriptive essays in Malaysia. Ning (2012) also did an empirical study, collecting English writing samples from graduate students at a university in China, analyzing the error types and sharing some suggestions on how to improve the students' writing.

These studies benefited the field in that they applied Error Analysis theory in order to classify errors based on various criteria, analyze the errors in specific ways and provide suggestions for English teaching and students' learning. No previous study to date, however, has focused on the comparison of errors between Chinese and Korean English learners. This paper focuses on the comparative analysis of errors in English essays between Chinese and Korean university students.

\section{RESEARCH METHOD ${ }^{1}$}

\section{A. Research Questions}

Through the identification and description of errors made by Chinese and Korean university students, this study tries to identify the similarities and differences between them, and then provide some suggestions based on this analysis for English teaching in China and Korea.

\section{B. Subjects}

A total of 168 essays, 84 essays written by Chinese and 84 essays by Korean university students, 39 males and 129 females, were collected and analyzed for the current study. These students were asked to write an argumentative essay within 30 minutes titled, "Do you agree or disagree with the following statement: 'Always telling the truth is the most important consideration in any relationship'?" This prompt was taken from the TOEFL iBT's independent writing topics for Asian test takers.

In order to make an equivalent comparison, which means Chinese and Korean university students being compared should have at least similar holistic writing proficiency, four raters were asked to score these essays after being trained based on the rubric for TOEFL iBT's independent writing. Then essays which received the same score were selected for further error analysis.

\section{Research Design}

\footnotetext{
${ }^{1}$ This paper is part of a larger mixed method study of English writing features of Chinese and Korean university students, which includes not only the analysis of errors, but also an analysis of linguistic features of their writing, both quantitatively and qualitatively.
} 
According to Corder (1974) (as cited in Ellis and Barkhuizen, 2005, p.57), EA research includes five steps: collection of a sample of learner language, identification of learner errors, description of learner errors, explanation of learner errors, and evaluation of learner errors. This is the research procedure that was followed in the current research.

As mentioned, this study adopted Kim (2009)'s error classification system, derived from Dulay and Burt's linguistic classification of errors. Four types of errors: misformation, omission, addition, and other, with their subcategories are identified and coded in this study. According to Dulay, Burt and Krashen (1982), "mistakes" need to be distinguished from "errors." Mistakes are linguistic disfluencies caused by fatigue or inattention, while errors are the results of students' language proficiency levels. But it is often difficult to distinguish an error from a mistake. Therefore, in this paper, error is used to refer to "any deviation from a selected norm of students' writing performance, no matter what the cause of the deviation might be" (p.139). Three coders, one Chinese English teacher, one Korean English teacher, and one American English teacher, worked together to identify all the errors in the student essays. Errors were further analyzed with the help of the qualitative data analysis software NVivo.

\section{RESULTS AND DisCUSSIONS}

A total of 3, 241 errors were identified in all. Of them, 1, 393 errors were found in essays written by the Chinese English learners (CE), while 1, 848 errors were found in essays written by the Korean English learners (KE). Tables below provide a comparative analysis of the errors made by $\mathrm{CE}$ and $\mathrm{KE}$ respectively in terms of misformation, omission, addition, and other categories.

\section{A. Misformation}

According to Dulay, Burt and Krashen (1982), misformation errors are characterized by "the use of the wrong form of the morpheme or structure" (p.158). In this paper, misformation is further analyzed from subcategories such as noun misformation, verb misformation, article misformation, etc. Table 1 shows the error frequency of misformation for both the $\mathrm{CE}$ and $\mathrm{KE}$.

TABLE I.

ERROR FREQUENCY OF MISFORMATION

\begin{tabular}{|c|c|c|}
\hline Number of errors in CE (rank) & Categories & Number of errors in KE (rank) \\
\hline $56(3)$ & Verb & $79(1)$ \\
\hline $56(3)$ & Preposition & $69(2)$ \\
\hline $53(5)$ & Ill-formed sentence structure & $67(3)$ \\
\hline $65(1)$ & Tense & $55(4)$ \\
\hline $57(2)$ & Noun & $30(7)$ \\
\hline $43(6)$ & Verb inflection & $30(7)$ \\
\hline $40(7)$ & Subject verb agreement & $42(5)$ \\
\hline $24(10)$ & Article & $31(6)$ \\
\hline $27(8)$ & Adjective & $15(14)$ \\
\hline $26(9)$ & Adjective form & $19(11)$ \\
\hline $19(13)$ & Modal verb & $26(9)$ \\
\hline $24(10)$ & Noun form & $24(10)$ \\
\hline $20(12)$ & Pronoun & $17(12)$ \\
\hline $19(13)$ & Run-on sentence & $5(23)$ \\
\hline $17(15)$ & Single and plural form & $13(15)$ \\
\hline $6(20)$ & Passive voice construction & $16(13)$ \\
\hline $14(16)$ & Infinitive & $7(21)$ \\
\hline $13(17)$ & Conjunction & $10(17)$ \\
\hline $8(19)$ & Plural agreement & $13(15)$ \\
\hline $10(18)$ & Possessive adjective & $8(19)$ \\
\hline $4(24)$ & Relative pronoun & $10(17)$ \\
\hline $6(20)$ & Phrasal verb & $8(19)$ \\
\hline $6(20)$ & Pronoun inflection & $3(25)$ \\
\hline $6(20)$ & Adverb & $6(22)$ \\
\hline $1(28)$ & Determiners & $5(23)$ \\
\hline $4(24)$ & Adverbial & $3(25)$ \\
\hline $4(24)$ & Auxiliary verb & $2(28)$ \\
\hline 0 & Adverb form & $3(25)$ \\
\hline $1(28)$ & Gerund & $2(28)$ \\
\hline $2(27)$ & Parallel structure & $1(30)$ \\
\hline 0 & Possessive-'s & $1(30)$ \\
\hline
\end{tabular}

Table 1 shows the occurrence of similar error types and frequencies for both CE and KE. The ten most frequently made errors are almost identical for in $\mathrm{CE}$ and KE. They are the misformation of verbs, nouns, prepositions, articles, verb inflection, noun forms, subject verb agreement and ill-formed sentence structures. It turns out that both Chinese and Korean learners are equally likely to make mistakes in terms of tense, the selection of accurate verbs and nouns, the usage of prepositions and articles, subject verb agreement, the inflection of verbs and sentence structure. Some sample errors are as follows (the words in the brackets are corrections): 
1) If one [a] person always lie [lies] to other people, others will fell [feel] hatred. (CE 30) (Article misformation, subject-verb agreement misformation, verb misformation)

2) For instance, many couples end up in a fighting [fight], because they are not experts at hiding personal thoughts. (KE 25) (Noun misformation)

3) For [From] my standpoint, it is very important to tell the truth in the relationship. (CE 67) (Preposition misformation)

4) In [On] the other hand, always telling the truth may hurt others. (KE 45) (Preposition misformation)

5) As time went by, he became a [an] introvert [introverted] person and [was] still stupid [reclusive]. (CE 10) (Article misformation, adjective form misformation, omission of 'be' verb, awkward expression)

6) Sometimes saying [telling] a lie is a kind of self-protection (KE 33) (Verb misformation)

7) Most of time, honest [honesty] plays an important role in our life. (CE 6) (Misformation of noun form)

8) In my opinion, the true [telling the truth] is very important.[,] Because [because] lie is someday revealed [lies are usually revealed]. (KE 4) (Misformation of noun form, fragment, single and plural form)

9) For example, some business information are [is] extremely important for our groups. (CE 2) (Misformation of subject verb agreement)

10) Telling the truth [In telling the truth], we must be honesty [Honest]. (CE 22) (Ill-formed sentence structure, adjective misformation)

Additionally, both the Chinese and Korean learners committed similar errors in their selection of adjectives and pronouns. Some sample errors are as follows:

1) For example, if one girl ask [asks] you: "Hey, look at me. Is (Does) that dress suit on [delete 'on'] me?" we [I] response [respond] "That dress suits you well." though the dress is terrible. (KE 50) (Misformation of verb reflection, misformation of modal verb, misformation of pronoun, misformation of verb)

2) We must be honesty [honest] to our classmates and our teachers. (CE 12) (Adjective misformation)

Why do most Chinese and Korean university students make similar errors in verbs, nouns, adjectives, prepositions, etc.? Does it prove that general learning structures exist during the process of second language learning? Based on the Creative Construction Hypothesis, VanPatten and Benati (2010) summed up that, and more specifically morpheme studies, learners tend to go through the same stages in order to acquire a given structure of the target language, regardless of their L1 background.

However, the question is, since these Chinese and Korean university students had learned English for at least six years, why were they still making errors in terms of misformation of verbs, nouns, prepositions, etc.? Shim (2006) noted that in many cases Korean English learners' errors were not explicitly identified and corrected and thus became fossilized and that this fossilization seriously interfered with their fluency and accuracy in acquiring L2. This suggests that Korean university students need to learn through form-focused instruction so they can pay more attention to form and grammar. Fossilizable linguistic phenomena, as Selinker (1982) defines them, are "linguistic items, rules, and subsystems which speakers of a particular L1 tend to keep in their interlanguage relative to a particular target language, no matter what the age of the learner or amount of explanation and instruction he receives in the target language" (p. 215). Though the Chinese and Korean university student had learned English for a relatively long time, they must have failed to fossilize some rules of English and grammar correctly in practice because they were not corrected immediately after they made these errors. It is probable that fossilization was the main reason for their misuse of verbs, nouns or prepositions. One more explanation is that although they had learned English for a long time, the Chinese and Korean English learners were still EFL learners, which means they had not had sufficient opportunity to be exposed to English. In other words, they had limitations to their ability to practice their English due to their being surrounded by only Chinese and Korean. Whatever the reason, the Chinese and Korean English learners needed to pay more attention to these errors in order to become more proficient speakers.

One error category which revealed an obvious difference between the Chinese and Korean English learners was that of the run-on sentence. A run-on sentence refers to when two or more independent clauses are joined together without appropriate punctuation mark or conjunction. The Chinese English learners had more run-on sentences than the Korean English learners. Some run-on sentence examples of CE were as follows:

1) In our lives, teamwork is very important, we should turn into unification so as to make our work more efficient, so we must be honest to tell the truth and loyal to any member. (CE17)

A coordinating conjunction 'so' may be needed after the first clause 'teamwork is very important' to present a consequence, 'so we should turn into unification so as to make our work more efficient'.

2) Maybe someone say something bad on your friends, he/she will hate the guy. (CE22)

This sentence is ambiguous. It has more than a conjunction problem. But one thing this sentence needs, at least, is a coordinating conjunction such as 'and', to show a non-contrasting idea. The sentence may sound better if it reads 'Maybe someone said something bad about your friends and this person actually hates your friends...' Another way to fix the sentence would be to create two separate sentences: 'Maybe someone said something bad about your friends. In other words, he/she hates your friends'. 
3) a patient gets a cancer, the doctor often don't tell the truth directly but tell the patient's family to let them choose it. (CE70)

For this sentence, a subordinating conjunction 'if' is missing to introduce a dependent clause: 'If a patient is diagnosed with cancer, the doctor often doesn't tell the truth directly but tells the patient's family, letting them decide whether to tell the patient or not'.

4) If we keep a "secret", we always do everything cautiously as if we are doing something bad, in reality, we are not. (CE74)

Basically, this sentence lacks a 'but' to show contrast: 'but in reality we are not'. Or the student could also have chosen to use a semicolon after the word 'bad' to separate the sentences, while still maintaining the vital connection between the two clauses.

In all, there are three basic remedies for these sample run-on sentences: use conjunctions, use a semicolon, or use separate sentences. No matter which of these remedies is used, the revised sentence would be clearer.

Why do Chinese English learners write more run-on sentences? Some other researchers have noticed this phenomenon as well. Liu (2011) claimed that roughly seventy-five percent of Chinese sentences are comprised of more than two phrases separated by commas: comma splices and independent clauses joined together without any conjunction. Xue and Yang (2012) have pointed out in this regard that the Chinese comma is very ambiguous and multi- functional because, in some contexts, it can identify the boundary of a sentence just as does a period, a question mark or an exclamation mark.

According to Ma (1999), Chinese is a language that focuses more on semantics whereas English focuses more on syntax. Therefore, English is more complex grammatically requiring conjunctions to form compound or complex sentences, while Chinese is more implicitly coherent having fewer conjunctions. One researcher (anonymous, n.d.) did a very detailed comparison of features of Chinese and English. He featured English and Chinese as rigid vs. supple, hypotactic vs. paratactic, and complex vs. simplex.

TABLE II.

ENGLISH LANGUAGE FEATURES VS. CHINESE LANGUAGE FEATURES

\begin{tabular}{|l|l|}
\hline rigid vs. supple & $\begin{array}{l}\text { The rigidity of English means it is formal, requiring a complete sentence structure and SV concord, while Chinese enjoys the } \\
\text { suppleness of a flexible sentence structure and pays more attention to semantic coherence. }\end{array}$ \\
\hline $\begin{array}{l}\text { hypotactic vs. } \\
\text { paratactic }\end{array}$ & $\begin{array}{l}\text { Hypotaxis refers to the dependent or subordinate construction or relationship of clauses with connectives. Parataxis means the } \\
\text { arranging of causes one after another without connectives to show the relation between them. English more often employs overt } \\
\text { cohesion, frequently using various cohesive ties such as coordinators, subordinators etc. }\end{array}$ \\
\hline $\begin{array}{l}\text { complex vs. } \\
\text { simplex }\end{array}$ & $\begin{array}{l}\text { English sentences display an "architecture style" that uses many longer or subordinate structures, while Chinese is marked by a } \\
\text { "chronicle style" with frequent use of shorter or composite structures. }\end{array}$ \\
\hline
\end{tabular}

This table explains why the Chinese English learners frequently use many run-on sentences. Their use of run-on sentences is the result of heavy L1 negative transfer.

\section{B. Omission}

Dulay, Burt and Krashen (1982) pointed out that omission errors are characterized by "the absence of an item that must appear in a well-formed utterance" (p.154). For instance, one student wrote: Always telling the truth cannot be (the) most important consideration in any relationship. Obviously, this student omitted the article 'the' which is needed with a superlative adjective. Table 3 shows the error frequency of omission for both the $\mathrm{CE}$ and $\mathrm{KE}$.

TABLE III.

ERROR FREQUENCY OF OMISSION

\begin{tabular}{|l|l|l|}
\hline \multicolumn{2}{|c|}{ ERROR FREQUENCY OF OMISSION } \\
\hline $70(1)$ & Article & Number of errors in KE (rank) \\
\hline $56(2)$ & plural suffix-s & $177(1)$ \\
\hline $24(3)$ & Preposition & $100(2)$ \\
\hline $16(4)$ & Object & $45(3)$ \\
\hline $12(6)$ & 'be' verb & $22(4)$ \\
\hline $16(4)$ & Gerund & $17(5)$ \\
\hline $7(9)$ & Possessive adjective & $6(10)$ \\
\hline $11(7)$ & Subject & $13(6)$ \\
\hline $8(8)$ & Modal verb & $6(7)$ \\
\hline $4(13)$ & Auxiliary verb & $6(9)$ \\
\hline $7(9)$ & Noun & $3(16)$ \\
\hline $7(9)$ & Verb & $6(9)$ \\
\hline $7(9)$ & Adjective & 0 \\
\hline $4(13)$ & Adverb & $6(9)$ \\
\hline $2(16)$ & Relative pronoun & $5(13)$ \\
\hline $1(18)$ & Possessive-'s & $4(14)$ \\
\hline $3(15)$ & Infinitive & $4(14)$ \\
\hline 0 & Determiner & $2(17)$ \\
\hline $2(16)$ & Adverbial & 0 \\
\hline 0 & Passive voice & $1(18)$ \\
\hline
\end{tabular}

Note: Omission of conjunctions was diagnosed as a run-on sentence. 
Usage of articles and plural suffix-s were the two main grammatical categories which were most easily forgotten by both the Chinese and Korean English learners. However, in terms of the number of errors committed, the Korean English learners were more likely to omit articles, plural suffix-s and prepositions. Here are some examples.

1) Some people think divorce is really [a] bad thing. (KE74) (Omission of article)

2) People even think she is not [a] good girl. (KE76) (Omission of article)

3) In that case, telling [the] truth is not [a] good thing rather [an] obstacle to relationship(s). (KE7) (Omission of article and plural suffix-s)

4) Telling [the] truth between people's relationship may have good effect[s] or bad effect (s). (KE31) (Omission of article; Omission of plural suffix-s)

5) Many people often ask trivial question [s]. (KE35) (Omission of plural suffix-s)

6) So we must sometimes tell lie[s] for around people. [to people around us] (KE35) (Omission of plural suffix-s)

7) I don't agree [with] this statement. (KE40) (Omission of preposition)

8) So, I think we must be smart [about] whether [to] tell the truth or not. (KE17) (Omission of preposition)

9) You know something the truth likes a knife [with] which someone's heart'll be broken. (KE17) (Omission of preposition)

1. Different Use of Articles

There are no articles in the Korean language. That is why Korean English learners usually have a lot of problems with the English system of articles. The Korean language system lacks both the definite article "the" and the indefinite article "a". Korean generally relies on the context to communicate whether a noun is definite or indefinite. For example $^{2}$ : 개가 ${ }_{1}$ 밥을 2 먹어요 ${ }_{3}$ could mean: "The $\operatorname{dog}_{1}$ eats $_{3}$ rice $_{2}$ "if we know which dog; or "A dog eats $_{3}$ rice $_{2}$ " if it refers to some dog that is unspecified or new to the conversation.

The Chinese language also lacks an article system. Instead, determiners like 'this', 'that', 'these' or 'those' are used to define whether a noun is definite or indefinite. The difference in word sequence can also show the difference between definite and indefinite nouns. Zhang (2004) gave two examples to illustrate this point:

来 客 $_{2}$ 了 $_{3}$ 。 (A guest is coming)

客 2 来 $_{1}$ 了 $_{3}$ 。 (The guest is coming)

Therefore, the difference in the word sequence can specify whether a noun is definite or indefinite.

2. Different use of plurals

The use of plurals in the Chinese and Korean languages is the same. Plural forms do exist in both Chinese and Korean. The word '们 (men)' in Chinese and '들 (deur)' in Korean are used as the plural forms of these nouns. They can be used together with determiners like 'these' or 'those' or with possessive adjectives like 'my', 'her', or 'our,' etc. However they can never be used together with specific numbers. For example:

In Chinese: 我 ${ }_{1}$ 有 ${ }_{2}$ (三只) 猫 $_{4}$ 。 (I1 have three $_{3}$ cats $_{4}$ ).

猫 (mao) means cat in Chinese, but since there is a specific number ('three') in the sentence, the plural form '们'(men) can not be added after the noun. The same principle applies to the Korean language as well. That is why Chinese and Korean English learners always have a tendency to forget to add the plural form after the noun, even though they may have become advanced English learners. The L1's influence seems to continue to hang on to some extent.

3. Different use of prepositions

The Korean language has postpositions instead of prepositions. The postpositions are usually attached at the end of the noun. For example, instead of saying "I am going to school with you", Korean kids would say "I am going to school you with". In other words, English is said to be "right branching", while Korean is consistently "left branching".

Like English, the use of prepositions in Chinese is also very complicated. It has prepositions for time, place, direction, agent and instruction. Prepositions can be a word or a phase. In Chinese, prepositions can be used before or after the noun, depending on the meaning difference. For example, instead of saying "I am in the room," Chinese people tend to say "I am room in," which is the same for Korean in this case.

The complexity of the use of prepositions in English also makes it difficult for Chinese and Korean English learners to master them when they write in English.

\section{Addition}

Addition errors are the opposite of the omissions category. According to Dulay, Burt and Krashen (1982), they are characterized by "the presence of an item which must not appear in a well-formed utterance" (p.156). Table 4 shows error frequency of addition for both the $\mathrm{CE}$ and $\mathrm{KE}$.

\footnotetext{
${ }^{2}$ From: http://www.declan-software.com/korean.htm
} 
TABLE IV.

ERROR FREQUENCY OF ADDITION

\begin{tabular}{|l|l|l|}
\hline Number of errors in CE (rank) & Categories & Number of errors in KE (rank) \\
\hline $50(1)$ & Unnecessary word & $47(1)$ \\
\hline $40(2)$ & Article & $26(3)$ \\
\hline $18(4)$ & Preposition & $28(2)$ \\
\hline $19(3)$ & Conjunction & $16(4)$ \\
\hline $11(6)$ & 'be' word & $16(4)$ \\
\hline $12(5)$ & Plural suffix-s & $6(7)$ \\
\hline $7(7)$ & Modal verb & $7(6)$ \\
\hline $2(8)$ & Object & $4(8)$ \\
\hline $2(8)$ & Possessive adjective & $4(8)$ \\
\hline 0 & Auxiliary verb & $3(10)$ \\
\hline $1(10)$ & Possessive-'s & $2(11)$ \\
\hline
\end{tabular}

Addition of unnecessary words was the most frequent error for both the $\mathrm{CE}$ and KE. Articles, prepositions and conjunctions were also the main problems that both the Chinese and Korean English learners encountered in terms of word addition. Here are some examples:

1) We prefer the people who always telling the truth. (CE24) (Addition of article)

2) This is the true love. (CE24) (Addition of article)

3) Truth is Important in Everytime. (KE11)(Addition of preposition)

4) At school, if we tell truth with our classmates and we'll have good friends. (CE21)(Addition of conjunction)

5) In our life, we faced so many situations. And also we faced many decisions. So If you want to deal this problems very well, you have to various answers for them. (CE21)(Addition of conjunction)

6) Old man's eyes were blind. (CE85) (Addition of unnecessary word)

7) I am to agree with "Always telling the truth is the most important consideration in any relationship" this sentence. (KE14) (Addition of unnecessary word)

If we compare Table 3 with Table 4, we can find that students omitted more articles and plural forms than those they added. The problems still lie in the complexity of the English article and plural form system. This suggests that since the use of articles and plural forms are so different from their L1, the students may have paid more attention to their use. It just turned out that sometimes their use of them was wrong.

\section{The Error Category of 'Other'}

In this study, awkward expressions, not clear, misordering, fragments, and wrong vocabulary are all categorized in the error category of 'other.' Misordering errors, as Dulay, Burt and Krashen (1982) pointed out, are the incorrect placement of a morpheme or group of morphemes in an utterance (p.162). Table 5 shows the error frequency of other category of errors.

TABLE V.

ERROR FREQUENCY OF OTHER CATEGORY OF ERRORS

\begin{tabular}{|l|l|l|}
\hline Number of errors in CE (rank) & Categories & Number of errors in KE (rank) \\
\hline $115(1)$ & Awkward expression & $120(1)$ \\
\hline $90(2)$ & Not clear & $86(2)$ \\
\hline $34(4)$ & Misordering & $55(3)$ \\
\hline $41(3)$ & Fragment & $34(4)$ \\
\hline $27(5)$ & Wrong vocabulary & $11(5)$ \\
\hline
\end{tabular}

The frequency of errors shows that both of the Chinese and Korean English learners had problems expressing themselves in English. Therefore, their expressions were either awkward or not clear at all. All of them used many awkward expressions. Some samples are shown as follows:

1) If you know the truth disease that a patient causes. (KE11)

2) Let us suppose that is father and daughter with good relationship. (KE13)

3) Also a case of family is same. In this situation that one of your family member fail to entrance exam of the best university, the member's feeling will really frustrate. If you tell the member that "Your limitation is this level. So your labor was useless and you have to awake from dream that your ability is SNU. (KE48)

4) I think this essay is disagree. (KE 6)

5) Between both of you, you shouldn't hide any secrets. (CE26)

6) I don't resist to tell the truth. (CE28)

7) we must do the true things for them. (CE29)

Error differences between the Chinese and Korean English learners occurred most often with regards to the sequence of words and phrases. The Korean English learners made more 'misordering' errors than the Chinese learners. Some examples of misordering errors made by Korean English learners are provided below:

1) All of history are not truth. [Not all history is true.] (KE 11)

2) Always lying is not bad. [Lying is not always bad.] (KE 13)

3) I don't think that telling to lie is bad absolutely. [I don't think that telling lies is absolutely bad.] (KE 13) 
4) Because too blunt speaking or too frank speaking [speaking too bluntly or too frankly] can hurt listener. (KE 59)

5) Justice not works always. [Justice doesn't always work] (KE 74)

Chinese and English share basically the same sentence structure-SVO. The subject is the one who acts. The object is what receives the subject's action. However, Korean is classified as an SOV language, which means that the verb always comes at the end of sentence. This basic sentence structure difference influences the Korean English learners as they try to construct English sentences. As a result, errors may happen unconsciously. Von Stutterheim and Klein (1987, p. 196, as cited in Han, 2008, p. 63) stated that "the way in which the learner organizes his utterances is heavily influenced by the conceptual structure present and by the way in which this conceptual structure is encoded in the [native] language." Han (2008) claimed that the influence of L1, positive or negative, often continues into advanced stages of L2 learning. Take the following sentence for example:

All of history are [is] not truth. (Not all history is true.) (KE 11)

In the Korean language, if you want to say " $\operatorname{Not}_{1}$ all $_{2}$ history ${ }_{3}$ is $_{4}$ true $_{5}$ ", the sentence would be: 모든 ${ }_{2}$ 역사 ${ }_{3}$ 가 ${ }_{4}$ 진실한 것은 ${ }_{5}$ 아니다 ${ }_{1}$. The biggest difference in order is the position of the negative word "not". In Korean, it moves from the beginning of the sentence to the end. Because of this basic sentence structure difference, it is no wonder that the Korean English learners wrote the sentence wrongly: All2 of history3 is4 not1 truth5.

The point to be made is that these misordering errors may be in many cases because of the Korean English learners' L1. The way of speaking and writing in their L1 was transferred to their L2.

The next subcategory of other errors was wrong vocabulary. Here are some other examples Chinese learners made.

1) They don't want to make friends with liers. [liars] (CE 20) (Wrong vocabulary)

2) Nobody were like a person who is unhonesty [dishonest] or often tell lies. (CE 65) (Wrong vocabulary)

3) Truth can make us trust others and find sincereious [sincere] friends. (CE 35) (Wrong vocabulary)

On the one hand, these errors show that these English learners at least knew some principles of English grammar, such as the necessity of adding a suffix 'er' after a verb to make a noun, or adding a prefix 'un' before an adjective to make an opposite word. The problem here was that they tended to over-generalize the rule. But this also shows that they were in the process of building the new English structure in their mind. What they need to do now is to just keep working on improving their ability to apply these rules proficiently.

The final subcategory of other error is sentence fragments. The followings are several examples.

1) Since you need to tell a lie on some occasions and you have not choice. (CE3) (Fragment)

2) But not any relationship. (CE1) (Fragment)

3) Just as always telling the truth isn't the most important consideration in any relationship. (CE61) (Fragment)

The fragment error category is still subject to the L1's negative influence. However, I believe it could be cured after English learners' self-rediscovery process or with teachers' help.

\section{CONCLUSIONS}

This study undertook a detailed comparative linguistic error analysis based on the error classification system developed by Kim (2009). Linguistic errors were identified and coded with the help of NVivo. The study's main findings were as follows: 1) In terms of misformation, both the Chinese and Korean learners are likely to make a similar number of mistakes in their use of tense, the selection of accurate verbs and nouns, the usage of preposition and article, subject verb agreement, the inflection of verbs, the sentence structures, conjunctions, the selection of adjectives and pronouns, plural agreement and plural forms. It suggests that in the process of second language acquisition, some common errors may happen regardless of learners' first language background. 2) One obvious difference was with regards to the run-on sentence. The Chinese learners had more run-on sentences than the Korean learners. It was hypothesized that this was due to the different features of the Chinese language, in which commas are frequently used to serve the added functions of conjunctions or even periods. 3) In terms of omission, article and plural suffix-s were found to be two main grammatical features easily forgotten by both the Chinese and Korean learners. It was suggested that this may also be because of the negative L1 transfer from Chinese and Korean. In Chinese and Korean, articles do not exist. The usage of the plural form is also different from that of English. 4) In terms of addition and omission, use of prepositions was one of the main problems that both Chinese and Korean encountered. It was proffered that the reason for this also lies in the complex and different usage of preposition in both Chinese and Korean. 5) Finally, the Korean learners had more "misordering" errors than the Chinese learners, which may be accounted for basically because the Chinese language structure is closer to that of English than Korean is.

Mitchell and Myles (2004, as cited in Benati and Lee, 2008, p.1) commented that there is no unified or comprehensive theory as to how second languages are learned, although this is presently a burgeoning field of research. Through the detailed description and comparative analysis of possible reasons for errors, this study supports the plausibility of the contrastive analysis hypothesis $(\mathrm{CAH})$ and creative construction hypothesis $(\mathrm{CCH})$. $\mathrm{CAH}$ concentrates on the role of learners' first language in second language acquisition. Some errors such as run-on sentences, the omission of articles and plural suffix-s, and misordering all revealed what appeared to be the influence of learners' first language on L2 acquisition. CCH holds that learners' second language acquisition process is very creative, with no relation to L1 background. The common errors could be the result of $\mathrm{CCH}$, very creative innovations in the learners' efforts to learn L2, or they could be merely the result of lack of knowledge of L2. Therefore, further study is needed to 
explore the extent to which common errors are the result of $\mathrm{CCH}$ creative learning versus a mere lack of familiarity with L2. That is, no matter how advanced their English level was, no matter whether the learners were Chinese or Korean, they still had many commonalities in terms of their problems in the use of verbs, nouns, adjectives, etc. Some errors, as explained, may have thus been due to the L1 influence, while others were common errors that may be encountered regardless of one's nationality.

Since errors may be caused by the L1 influence or by learners' self-construction, teachers, firstly, need to figure out the causes of these errors. Are they errors or just mistakes? Are these errors influenced by learners' L1 or just by their creative overgeneralization of some grammatical rule? Secondly, having a correct attitude towards learners' errors is also very important. The learner's L1 could have both positive and negative influence on L2 learning. Besides, some errors could be a positive indicator of learners' L2 learning progress. As previously noted, errors like overgeneralization of negative prefix 'un' in the word 'dishonest' could merely indicate that learners are actively building their own grammatical understanding cognitively. They could realize their errors through teachers' instruction individualized coaching or even by themselves. Therefore, teachers should treat learners' errors in a more comprehensive way. As long as L2 learners have adequate exposure and practice in L2 writing, with the help and consistent feedback of teachers, they could finally internalize the L2 grammatical rules and consequently the number of errors could be reduced.

A limitation of this study is that it my be very hard at times to determine what category a specific error belongs to. For instance, some run-on sentences could also be categorized as omission of conjunctions. So there might be some mistakes in coding these errors. However, the study shows a general picture of the types of errors made by the Chinese and Korean university students, which can definitely prove helpful for English writing teaching and learning in China and Korea.

\section{REFERENCES}

[1] Anonymous. (n.d.) English vs. Chinese: Ten pairs of features. Retrieved from http://www.google.com/url?sa=t\&rct=j\&q=english $\% 20 \mathrm{vs} \% 20$ chinese $\% 20$ ten $\&$ source=web\&cd=1\&cad=rja\&ved=0CC $8 \mathrm{QFj} A$ A\&url=http\%3A\%2F\%2Fspdc.shnu.edu.cn\%2F1000011102\%2F3\%2Ftan\%2F2.ppt\&ei=6j5rUczYBYvRqwHfl4GgDg\&usg= AFQjCNHsrnrfcHDe_mKLrU6w1dlbYJLGFw\&bvm=bv.45175338,d.b2I (accessed 05/01/2013).

[2] Benati, A. G. \& Lee, J. F. (2008). Grammar acquisition and processing instruction: Secondary and cumulative effects. UK: Multilingual Matters.

[3] Corder, S. P. (1974). Error analysis. In J. Allen and S. Corder (eds.), The Edinburgh Course in Applied Linguistics Volume 3: Techniques in Applied Linguistics. Oxford: Oxford University Press.

[4] Corder, S. P. (1981). Error analysis and interlanguage. Oxford: Oxford University Press.

[5] Dulay, H. \& Burt, M. (1973). Should we teach children syntax? Language Learning 23, 245-258.

[6] Dulay, H. \& Burt, M. (1974). Natural sequences in child second language acquisition. Language Learning 24, 37-53.

[7] Dulay,H., Burt, M., \& Krashen, S. (1982). Language two. Oxford: Oxford University Press.

[8] Ellis, R. (1985). Understanding second language acquisition. Oxford: Oxford University Press.

[9] Ellis, R. \& Barkhuizen, G. (2005). Analysing learner language. Oxford: Oxford University Press.

[10] Ellis, R. (2008). The study of second language acquisition. Oxford: Oxford University Press.

[11] Han, Z-H. (2008). Understanding second language process. UK: Multilingual Matters.

[12] Heydari, P. \& Bagheri, M. S. (2012). Error analysis: Sources of L2 learners' errors. Theory and Practice in Language Studies $2.8,1583-1589$.

[13] Kim, M. S. (2009). An error analysis of a learner corpus of written and spoken English produced by Korean university students. (Unpublished doctoral dissertation). Korea University, South Korea.

[14] Lado, R. (1957). Linguistics across cultures. Ann Arbor: The University of Michigan Press.

[15] Liu, X. (May, 2011). The not-so-humble 'Chinese comma' improving English CFL students' understanding of multi-clause sentences. Proceedings from: The 9th New York International Conference on Teaching Chinese, New Jersey.

[16] Ma, G. H. (2002). The comparative analysis of the writing linguistic features between Chinese and American university students. Foreign Language Teaching and Research 34.5, 345-349.

[17] Mitchell, R. \& Myles, F. (2004). Second language learning theories. London: Hodder Arnold.

[18] Muriungi, P. K., Mukuthuria, M. \& Gatavi, M. (2011). Education and language: Errors in English language and their remedies. The Journal of Language and Linguistic Studies 7.2, 87-116.

[19] Ning, M. (2012). Implications of interlanguage error analysis and research on English language testing and teaching. Higher Education of Social Science 2.2, 4-7.

[20] Seliner, L. (1972). Interlanguage. IRAL 10.2, 209-231.

[21] Selinker, L. (1992). Rediscovering interlanguage. London and New York: Longman.

[22] Shim, Y-S. (2006). An error analysis of Korean college students' English used in online chat tasks. English Language and Linguistics 22, 71-91.

[23] VanPatten, B. \& Benati, A. G. (2010). Key terms in second language acquisition. London: Continuum International Publishing Group.

[24] Von Stutterheim, C. \& Klein, W. (1987). A concept-oriented approach to second language studies. In Pfaff. C (ed.), First and second language acquisition processs. Cambridge, MA: Newbury House, 191-205.

[25] Xing, D-P. (2007). Error analysis in China English language teaching. Journal of Cambridge Studies 2.2, 34-36.

[26] Yahya, A., Ishak, H., Zainal Z., Faghat, L.J. \& Yahaya, N. (2012). Error analysis of L2 learners' writings, a case study. Proceedings from: 2012 International Conference on Language, Medias and Culture. IPEDR, 33, pp. 114-118, IACSIT Press, Singapore. 
[27] Yang, W. (2010). A tentative analysis of errors in language learning and use. Journal of Language Teaching and Research 1.3, 266-268.

[28] Yang, Y., \& Xue, N. (July, 2012). Chinese comma disambiguation for discourse analysis. Proceedings of the 50th Annual Meeting of the Association for Computational Linguistics. Jeju, South Korea, pp. 786-794.

[29] Zhang, Z-Z. (2004). Theoretical rhetoric. Beijing: China Social Sciences Press.

Cui Zheng was born in Shandong in 1982. She received her Ph.D. in English education from Korea University in Seoul, South Korea in 2010. Her research interest lies in second language acquisition and language assessment. She is now a lecturer teaching in School of International Exchange, Shandong Normal University, China. She has several published articles in the field of TEFL and TCFL (teaching Chinese as a foreign language).

Tae-Ja Park received her Ph.D. from Korea University on speaking performance test tasks. She is now an instructor at Korea University in Seoul, South Korea, where she teaches English Education Policy at the Graduate School of Education. She is actively involved in publishing journal articles on the Korean EFL test takers' strategies. 